\title{
As vogais médias átonas finais no português brasileiro do século $\mathrm{XIX}^{1}$
}

\author{
Eliane da Rosa \\ Universidade Federal do Rio Grande do Sul \\ Data de recepción: 04/05/2015 | Data de aceptación: 03/09/2015
}

\begin{abstract}
Resumo:
Este trabalho buscou investigar o fenômeno de elevação das vogais médias átonas finais no português brasileiro do século XIX, a partir dos pressupostos teórico-metodológicos da Sociolinguística Histórica (Romaine 2009) e dos preceitos do Princípio do Uniformitarismo (Whitney 1867 / Labov 1994 / Labov 2008 / Joseph / Janda 2003). Para a execução da análise dos dados, foram utilizados dois tipos de dados empíricos: a evidência direta (obras metalinguísticas e didáticas) e a evidência indireta (correspondências da Coleção Varela). Os resultados da análise permitiram constatar que a elevação das vogais átonas finais /e/e /o/ já atuava no português brasileiro oitocentista.
\end{abstract}

\section{Palavras-chave:}

Elevação - vogais médias átonas finais - português brasileiro oitocentista.

\section{Sumário:}

1. Introdução. 2. Metodologia. 2.1 Os corpora. 2.2 A Coleta de dados. 3. Descrição e análise dos dados. 3.1 Análise dos dados da evidência direta. 3.1.1 Descrições da vogal átona final /e/ no português brasileiro. 3.1.2 Descrições da vogal átona final/o/ no português brasileiro. 3.2 Análise dos dados da evidência indireta. 3.2.1 Discussão sobre o valor fonético das vogais /e/ e /o/ nos registros escritos. 4. Conclusão. Referências bibliográficas. Apêndice.

\section{Final unstressed mid-vowels in Brazilian Portuguese of the 19th century}

\begin{abstract}
:
This paper investigated the Brazilian Portuguese final unstressed mid-vowels heightening based on the principles and methodologies of the Sociohistorical Linguistics (Romaine 2009) and according to the principles of the Uniformitarian Principle (Whitney 1867 / Labov 1994 / Labov 2008 / Joseph / Janda 2003). To the development of the analysis, it was used two kinds of empirical data: direct evidence (metalinguistic and didactic books) and indirect evidence (letters from Coleção Varela). The results of the analysis demonstrated that the heightening of the final unstressed vowels le/ and lo/ occurred in Brazilian Portuguese in the $19^{\text {th }}$ century.
\end{abstract}

1 Este artigo é uma adaptação da dissertação de mestrado As Vogais Médias Átonas Finais No Português Brasileiro do Século XIX: um estudo baseado em fontes de evidência direta e indireta (Rosa 2015).

Revista Galega de Filoloxí, 2015, 16: 147-167

ISSN 1576-2661 / e-ISSN 2444-9121 C UDC 
Key words:

Heightening - final unstressed mid-vowels - brazilian portuguese of the 19th century.

\section{Contents:}

1. Introduction. 2. Methodology. 2.1 Corpora. 2.2 Data collection. 3. Description and analysis of data. 3.1 Analysis of direct evidence data. 3.1.1 Descriptions of the final unstressed mid-vowel /e/ in brazilian portuguese. 3.1.2 Descriptions of the final unstressed mid-vowel /o/ in brazilian portuguese. 3.2 Analysis of indirect evidence data. 3.2.1 Discussion on the phonetic value of the vowels /e/ e /o/ in written texts. 4. Conclusion. References. Appendix. 


\section{Introdução}

$\mathrm{Na}$ atualidade, diversos estudos têm sido desenvolvidos com o intuito de investigar processos de variação e mudança nas línguas por meio da língua falada. No entanto, especialistas em investigações linguísticas de cunho histórico (Cardeira 2009 / Marquilhas 2003 / Carvalho 2005 / Naro 1973 / Romaine 2009 / Lass 2000 / Montgomery 2007 / Schneider 2002) afirmam que não é somente através de amostras de fala que é possível estudar processos de variação e mudança, mas também por intermédio de amostras de língua escrita. Os registros escritos, além de serem as testemunhas de primeira ordem de um passado linguístico mais distante, compõemse de formas ortográficas que podem estar sujeitas à interpretação linguística.

Estudos (Naro 1973 / Carvalho 1984 / Carvalho 2005 / Fonte 2010 / Monaretto 2013) sobre as vogais médias átonas finais, realizados com amostra de língua escrita, apontam que a instabilidade da realização das referidas vogais $(/ \mathrm{e} />[\mathrm{e}] \sim / \mathrm{e} />$ $[\mathrm{i}] ; / \mathrm{o} />[\mathrm{o}] \sim / \mathrm{o} />[\mathrm{u}])^{2}$ não é uma característica somente do português brasileiro moderno e que o fenômeno de elevação dessas vogais pode ser observado em períodos anteriores ao século XXI.

Diante de tais constatações, a presente pesquisa tem por objetivo investigar o processo de elevação das vogais átonas finais /e/ e /o/ no português brasileiro oitocentista, a partir dos pressupostos teórico-metodológicos da Sociolinguística Histórica (Romaine 2009) e dos preceitos do Princípio do Uniformitarismo (Whitney 1867 / Labov 1994 / Labov 2008 / Joseph / Janda 2003).

\section{Metodologia}

\subsection{Os corpora}

Os corpora do presente estudo foram compostos a partir de dois tipos de dados empíricos: a evidência direta e a evidência indireta (Maia 1986 / Lass 2000 / Montgomery 2007 / Schneider 2002 / Penke / Rosenbach 2007 / Beal 2012 / Schalley 2012). Consideram-se como fontes de evidência indireta os registros escritos, porque os autores desses registros fornecem informações acerca do estado da língua de maneira inconsciente. Enquanto as fontes de evidência direta consistem nas declarações de gramáticos, ortógrafos, ortoepistas e elocucionistas, porque estes têm a intenção de fornecer evidências linguísticas por meio da prescrição de normas.

2 Pesquisas (Bisol 2003 / Carniato 2000 / Mileski 2013 / Roveda 1998 / Schimitt 1987 / Silva 2009 / Vieira 1994 / Vieira 2002) realizadas com amostras de fala do Rio Grande do Sul revelam que a elevação das vogais /e/ e /o/ átonas finais atua como uma regra variável, com exceção da capital e região metropolitana nas quais o fenômeno atua de forma categórica. 
A escolha por estes dois tipos de dados empíricos se deve ao fato de que a partir do ano de 1500 o linguista tem a sua disposição não só fontes de evidência indireta como também fontes de evidência direta. De acordo com Schalley (2012: 8), a evidência direta dá suporte para a hipótese sem a intervenção de inferências, ao passo que a evidência indireta requer uma interpretação intermediária do linguista; pois os dados em si, muitas vezes, não sustentam a hipótese diretamente, portanto é importante o uso destes dois tipos de fontes de evidências para investigar um fenômeno linguístico no passado com mais precisão.

Desse modo, o corpus de evidência direta foi formado por 66 obras metalinguísticas e didáticas (Apêndice A) publicadas no século XIX, conforme ilustra o Quadro 1 a seguir:

\begin{tabular}{l|c}
\multicolumn{1}{c|}{ Tipo de Livro } & Séc. XIX \\
Gramática & 47 \\
\hline Compêndio de Ortografia & 03 \\
\hline Cartilhas de Alfabetização & 10 \\
\hline Dicionários & 04 \\
\hline Outros & 02 \\
\hline Total de livros & $\mathbf{6 6}$ \\
\hline
\end{tabular}

Quadro 1. Descrição do corpus de obras metalinguísticas e didáticas.

Para compor o corpus de evidência indireta, foram utilizadas 1351 correspondências produzidas no Estado do Rio Grande do Sul durante o século XIX. Estas correspondências fazem parte de um famoso acervo formado por mais de 10 mil documentos originais produzidos antes, durante e depois da Revolução Farroupilha ${ }^{3}$. Esta coleção, chamada de Coleção Varela, é composta por 25 caixas organizadas em ordem alfabética do sobrenome dos autores desses manuscritos e, atualmente, encontra-se sob a tutela do Arquivo Histórico do Rio Grande do Sul.

As correspondências da Coleção Varela foram escolhidas para constituir o corpus de evidência indireta em razão de esta coleção ser o acervo histórico mais importante no que diz respeito à história do Estado do Rio Grande do Sul. Ademais, este acervo tem uma grande quantidade de documentos produzidos por

3 Também conhecida como Guerra dos Farrapos, a Revolução Farroupilha foi um conflito regional, de caráter republicano, gerado por insatisfações junto ao governo imperial brasileiro. Esta guerra ocorreu na província de São Pedro do Rio Grande do Sul (atual Estado do Rio Grande do Sul) entre os anos de 1835 e 1845. 
indivíduos pertencentes a diversas classes sociais e que apresentam níveis de escolaridade variados.

Conforme os preceitos da Sociolinguística Histórica, as correspondências coletadas foram classificadas em dois períodos de tempo: Primeira Metade do século XIX, que corresponde ao período entre 1825 e 1850; e Segunda Metade do Século XIX, que corresponde ao período entre 1851 e 1900, conforme ilustra o Quadro 2:

\begin{tabular}{l|c|c}
$\begin{array}{c}\text { Divisão Cronológica do Corpus } \\
\text { de Correspondências }\end{array}$ & Ano & $\begin{array}{c}\text { Total de } \\
\text { Correspondências }\end{array}$ \\
\hline Primeira Metade do Século XIX & 1825 a 1850 & 992 \\
\hline Segunda Metade do Século XIX & 1851 a 1900 & 359 \\
\hline Total de correspondências & & $\mathbf{1 3 5 1}$ \\
\hline
\end{tabular}

Quadro 2. Divisão cronológica do corpus de correspondências

É relevante mencionar que não foi permitido examinar todos os manuscritos do acervo da Coleção Varela em virtude de não haver tempo hábil para tal procedimento. Desse modo, apenas examinou-se os manuscritos provenientes das caixas de $\mathrm{n}^{\circ} 01 \mathrm{a}$ de $\mathrm{n}^{\mathrm{o}} 18$, perfazendo um total de 10.141 manuscritos examinados. Além disso, cabe ressaltar que nem todos os documentos do referido acervo fizeram parte do corpus de análise do presente estudo. Esses manuscritos foram excluídos da análise em função das seguintes razões:

I) muitos desses documentos foram assinados por dois ou mais remetentes; por isso não é possivel verificar quem realmente os redigiu;

II) muitos dos documentos são cópias dos originais, portanto, não há identificação precisa de quem os copiou;

III) alguns desses documentos foram escritos em espanhol, que não é a língua de interesse deste estudo;

IV) muitos desses documentos não apresentam a descrição do ano em que foram redigidos impossibilitando sua classificação cronológica.

A justificativa para a utilização exclusiva de correspondências como objeto de análise reside no fato de este tipo de texto apresentar "menos" formalidade em relação aos demais tipos de textos encontrados nesta coleção. Segundo Schneider (2002: 75-76), apesar das cartas não representarem a fala, elas podem refletir muitos traços (características) da oralidade, isto é, as cartas podem apresentar indícios da pronúncia do indivíduo que as escreveu. Assim, por este motivo, os demais documentos (proclamações, procurações, alvarás, requerimentos, listas nominais, etc.) da referida coleção foram excluídos da análise deste estudo. 


\subsection{A Coleta de dados}

A metodologia adotada neste trabalho baseia-se no levantamento de informações sobre as vogais médias átonas finais em obras metalinguísticas e didáticas, e no levantamento grafemático das referidas vogais em manuscritos do século XIX.

Primeiramente, fez-se o levantamento de todas as informações a respeito das vogais átonas /e/ e /o/ em posição de final de palavra no corpus de obras metalinguísticas e didáticas. A partir desse procedimento, foram interpretadas todas as declarações que os estudiosos do passado fizeram sobre a pronúncia das vogais /e/ e /o/ em contexto átono final durante o século XIX. Com base nisso, foi possível determinar as prováveis realizações das referidas vogais no português brasileiro oitocentista.

Após esta etapa, partiu-se para a leitura paleográfica (Mendes 1953 / Berwanger / Leal 2012) das correspondências da Coleção Varela. Durante a leitura paleográfica, buscou-se identificar a ocorrência de palavras grafadas com $<\mathrm{i}>\mathrm{e}<\mathrm{u}>$ no lugar de $<\mathrm{e}>\mathrm{e}<_{\mathrm{O}}>$, respectivamente, em contexto de final de palavra não acentuada. Em seguida, segundo as premissas da análise grafemática (Maia 1986 / Lass 2000 / Montgomery 2007 / Schneider 2002), procurou-se interpretar os dados do corpus de correspondências com base no sistema vocálico átono final do português brasileiro atual no que diz respeito à relação entre os grafemas e os fonemas referentes às vogais médias átonas finais do século XIX. No entanto, quando os dados do português brasileiro atual não eram suficientes para interpretar essa relação entre os grafemas e os fonemas do português brasileiro oitocentista, recorreu-se à etimologia das palavras que causaram problemas de interpretação.

A partir desse procedimento, foram interpretados todos os dados obtidos referentes às vogais médias átonas finais do português brasileiro no século XIX. Como foram encontrados poucos dados que indicassem uma provável elevação da vogal átona final /e/, e nenhum dado sobre a vogal átona final /o/, optou-se por uma análise de caráter qualitativo, porque a baixa quantidade de dados obtidos impossibilitou a operacionalização de uma análise quantitativa dos mesmos. Embora não seja possível esboçar amplas generalizações sobre o fenômeno investigado, a análise qualitativa permite fazer observações razoáveis sobre o mesmo (Montgomery 1995 / McEnery / Wilson 200).

Além da baixa quantidade de dados, outra dificuldade surgiu ao longo desta análise no que se refere ao perfil sociocultural dos autores das correspondências da Coleção Varela. Como a grande maioria desses autores são pessoas desconhecidas, não foi possível obter informações ou registros documentais sobre a vida dos mesmos, e quando há informações, estas se apresentam de forma contraditória. 
Em consequência disso, decidiu-se por não traçar o perfil sociocultural dos autores das correspondências do corpus. Apesar de ser relevante delinear o perfil sociocultural de quem produziu os registros escritos, conforme recomenda os preceitos da Sociolinguística Histórica, é preciso lembrar que os registros escritos disponíveis, na maioria das vezes, sobrevivem por acaso e, por isso, acabam se tornando fragmentados e incompletos (Labov 1994 / Romaine 2009 / Joseph / Janda 2003). Neste caso, a tarefa do pesquisador é fazer o melhor uso destes "dados ruins" como recomenda Labov (1994).

Nesse sentido, acredita-se que a adoção desse caminho metodológico permite esboçar algum parecer sobre a atuação do fenômeno de elevação das vogais médias átonas finais no português brasileiro do século XIX.

\section{Descrição e análise dos dados}

\subsection{Análise dos dados da evidência direta}

Antes de iniciar a análise das fontes de evidência direta, isto é, dos testemunhos de gramáticos, ortógrafos, alfabetizadores e dicionaristas do passado, é necessário levar em consideração três pressupostos:

1. Os estudiosos consultados para o presente exame não eram foneticistas e nem fonólogos, com exceção do português Aniceto dos Reis Gonçalves Viana, autor de Ortografia Nacional (1904), que era foneticista e lexicólogo. Em períodos mais antigos, as descrições de pronúncia eram baseadas numa perspectiva ortográfica da língua, ou seja, buscava-se representar o som por meio de uma imagem gráfica, ou melhor, de um grafema. Por isso, estes depoimentos devem ser considerados como "observações". Além disso, é preciso ter em mente que em tempos anteriores ao século XX não havia metodologia científica adequada e nem tecnologia disponível para o estudo dos sons de uma língua.

2. Os relatos desses estudiosos podem indicar possíveis descrições da fala padrão que vigorava na época, e não da fala coloquial/não padrão. Esta hipótese reside no fato de os autores manifestarem, em seus livros, opiniões críticas contra a pronúncia do "vulgo", ou melhor, dos indivíduos iletrados ou com baixo nível de escolaridade. Diante disso, percebe-se que havia usos distintos da língua de acordo com a classe social e o nível de escolaridade. Portanto, as prescrições dos estudiosos sobre o uso "correto" ou "incorreto" da língua demonstram o que era considerado culto ou inculto em uma determinada época. 
3. As descrições que estes estudiosos fazem sobre os sons da língua portuguesa podem ser relatos de uma pronúncia latinizada. Em virtude do advento do pensamento renascentista (século XV) e pelo deslumbramento com a cultura clássica, os estudiosos antigos passaram a se preocupar em orientar o uso da língua portuguesa com base nas estruturas linguísticas do latim e do grego. Por causa disso, inúmeras gramáticas e dicionários da língua portuguesa começaram ser publicados a partir do século XVI com o intuito de prescrever normas com relação à forma "correta" de grafar e pronunciar a língua portuguesa. Para o gramático Andrade Junior (1884: 264), foi somente “depois que entrárão a ser cultivadas as linguas latina e grega, aquella principalmente, é que começou de polir-se a lingua portugueza e a adquirir a riqueza e suavidade que tanto a distinguem entre as linguas cultas da moderna Europa". Desse modo, considerase a possibilidade de os testemunhos dos estudiosos serem latinismos ou grecismos dos sons da língua portuguesa antiga.

Apesar de serem, na maioria dos casos, imprecisos, os testemunhos dos estudiosos que viveram no passado devem ser considerados como fontes relevantes para obterem-se evidências diretas a respeito do estado linguístico de uma língua em um determinado momento do passado (Maia 1986 / Penke / Rosenbach 2007 / Beal 2012 / Schalley 2012).

A presente análise consultou 66 obras metalinguísticas e didáticas publicadas durante o século XIX. É importante mencionar que nem todos os livros consultados serviram aos propósitos desta pesquisa em função de não apresentarem informações referentes à pronúncia das vogais médias em contexto átono final.

\subsubsection{Descrições da vogal átona final/e/ no português brasileiro}

Das 66 obras consultadas, somente 06 livros forneceram informações acerca do valor fonético da vogal átona final /e/ no português brasileiro oitocentista, conforme ilustra o Quadro 3 a seguir:

\section{Obras que Descrevem a Vogal Átona Final /e/ no Português Brasileiro}

Grammatica Analytica da Lingua Portugueza (Constancio D. M. 1831)

Grammatica Portugueza (Ribeiro 1881), (Ribeiro 1899)

Noções de Grammatica Portugueza (Silva Junior / Andrade 1887)

Grammatica Portugueza (Lapagesse 1889)

Grammatica Portugueza (Vilhena Alves 1895)

Quadro 3. Obras que descrevem a vogal átona final/e/ no PB. 
Diante dos dados expostos no Quadro 3, a presente análise iniciar-se-á com o testemunho do gramático Francisco Solano Constancio D. M. Em sua Grammatica Analytica da Lingua Portugueza, o autor declara que /e/ átono final era "surdo e quase mudo" (Constancio D.M. 1831: 7). Neste caso é importante lembrar que os estudiosos antigos utilizavam os termos "surdo" e "mudo" quando queriam se referir a uma vogal átona, cuja articulação era reduzida (Marquilhas 2015). Portanto, este depoimento de Constancio D.M. não permite verificar o valor fonético da vogal /e/ em posição átona final. No entanto, mais adiante, no capítulo Dos vicios de pronunciação mais notaveis, o autor comenta que:

Em outras provincias, e até em Lisboa, troca-se o $e$ em $i$, e o $i$ em $e$; v.g. minino, filiz, saudadis, por menino, feliz, saudades; e fezera, dezera, por fizera, dizera, etc.

Os Brasileiros, e especialmente os Bahianos, tem muitos vícios de pronunciação intoleraveis [...] mudão o e mudo em $i$, v.g. mi, por me, minino, por menino, di, por de (Constancio D. M. 1831: 259).

Considerando esta descrição, percebe-se que os portugueses e os brasileiros produziam a vogal átona final/e/ como vogal alta [i] no século XIX. Isto demonstra que o processo de elevação da vogal átona final /e/ atuava tanto no português brasileiro quanto no português europeu oitocentista.

Em Grammatica Portugueza (1881, 1899), Julio Ribeiro comenta que a vogal átona final /e/ era pronunciada como [i] pelos brasileiros e como [e] pelos portugueses. De acordo com Ribeiro (1881: 26 / 1899: 33), a maioria dos brasileiros pronunciam, por exemplo, "cidade - mosarabe - montes e valles" como " "cidadi - mosarabi montis $i$ vallis", enquanto os portugueses pronunciam as mesmas formas como "cidádê - mosárabê - montés e vallés" dando á voz terminal um som abafado, muito distincto de $i$ ". Com este testemunho, tem-se a evidência de que o fenômeno de elevação da vogal átona final /e/ já atuava no português brasileiro oitocentista.

Pacheco da Silva Junior e Lameira de Andrade (1887), em Noções de Grammatica Portugueza, não apresentam nenhuma informação sobre a pronúncia da vogal átona final /e/ no português brasileiro. Mas, no capítulo Anomalias grammaticaes - Idiotismos - Dialectos - Provincialismos - Brasileirismos, os autores declaram que era "muito commum a troca do $e$ pelo $i$ : - mi deixi, minino, que em Port[ugal] pron[unciam] sempre menino, etc." (Silva Junior / Andrade 1887: 511). Assim, com base nesta declaração desses autores, verifica-se que a vogal átona final /e/ era realizada como vogal alta no português brasileiro oitocentista. Portanto, podese dizer que o processo de elevação da vogal média átona final /e/ já ocorria no português do Brasil durante o século XIX. 
Em Grammatica Portugueza, Léon Eugênio Lapagesse (1889: 137) explica que <e> deveria soar "quase como $i$ " quando estivesse exercendo a função de conjunção, mas se a referida vogal estivesse em final de palavra, este $<$ e $>$ deveria ser "mudo", como em "E este ( $i$ est)", por exemplo. Cabe ressaltar novamente que o termo "mudo" era utilizada para se referir a vogal átona, que tinha a articulação reduzida. Com base neste depoimento de Lapagesse, infere-se que a vogal átona final /e/ era elidida no português brasileiro do século XIX. É interessante destacar que somente este autor, dentro todos os autores consultados, mencionou que a vogal /e/ era elidida em contexto átono final.

Francisco Ferreira de Vilhena Alves (1895: 10), na obra Grammatica Portugueza, menciona que a vogal átona final /e/ tinha o valor quase de [i], como em bondade. Considerando esta declaração, acredita-se que o processo de elevação da vogal átona final /e/ estava atuando no português brasileiro durante o século XIX.

Com base nos testemunhos dos gramáticos citados anteriormente, é possível postular que, ao longo do século XIX, a vogal /e/ apresentava variação na pronúncia quando esta se encontrava em contexto átono final, conforme ilustra a Tabela 1 a seguir:

\begin{tabular}{c|c}
$\begin{array}{c}\text { Valor da Vogal Média } \\
\text { Átona Final no PB }\end{array}$ & Século XIX \\
\multirow{2}{*}{ Vogal /e/ $>$} & {$[\mathrm{i}]$} \\
\cline { 2 - 2 } & {$[\varnothing]$} \\
\hline
\end{tabular}

Tabela 1. O valor fonético da vogal /e/ no PB segundo os estudiosos do passado.

Os dados expostos na Tabela 1 demonstram que, no século XIX, a vogal /e/ apresentava duas variantes: uma como vogal alta [i], e outra como [Ø]. Levando em consideração que apenas um autor, Lapagesse (1899), mencionou que a vogal /e/ era elidida em contexto átono final, conjectura-se que a elevação da vogal átona final /e/ era o fenômeno predominante no português brasileiro.

Nesse sentido, os dados obtidos na presente análise confirmam que o processo de elevação da vogal átona final /e/ já atuava no português brasileiro desde século XIX. Portanto, pode-se afirmar que este fenômeno não é recente na história do português brasileiro.

\subsubsection{Descrições da vogal átona final /o/ no português brasileiro}

Dos 66 livros analisados, apenas 03 obras apresentaram informações sobre o valor fonético da vogal átona final /o/ no português brasileiro oitocentista, como mostra o Quadro 4 a seguir: 
Obras que Descrevem a Vogal Átona Final /o/ no Português Brasileiro

Grammatica Analytica da Lingua Portugueza (Constancio D. M. 1831)

Grammatica Portugueza (Lapagesse 1889)

Grammatica Portugueza (Vilhena Alves 1895)

Quadro 4. Obras que descrevem a vogal átona final/o/ no PB.

Diante dos dados expostos no Quadro 4, a presente análise iniciar-se-á com o testemunho de Francisco Solano Constancio D. M.. Em sua Grammatica Analytica da Lingua Portugueza (1831: 8), o autor declara que /o/ átono final era "surdo e quasi soando u, como nas finaes de do, modo, cobrio, desceo, etc". É interessante ter mente que o termo "surdo" era utilizado pelos estudiosos antigos quando estavam se referindo a uma vogal átona, cuja articulação era reduzida (Marquilhas 2015), e não que a mesma era elidida. Desse modo, a partir do depoimento do autor, acreditase que a vogal átona final /o/ estava sofrendo um processo de elevação no português brasileiro do século XIX.

Em Grammatica Portugueza, Léon Eugênio Lapagesse (1889: 137) descreve que " $o$ artigo e $o$ final das palavras tem o som de $u$, ex.: O livro ( $u$ livru)". Diante disso, presume-se que a vogal átona final /o/ era realizada como vogal alta no português brasileiro do século XIX. A partir disso, verifica-se que o fenômeno da elevação da vogal /o/ já atuava no português do Brasil.

Francisco Ferreira de Vilhena Alves (1895: 10), em Grammatica Portugueza, menciona que a vogal átona /o/ tinha o valor quase de [u], como em livro. Com base neste relato do autor, verifica-se que a referida vogal estava sofrendo um processo de elevação em contexto átono final no português brasileiro do século XIX.

Com base nos testemunhos dos gramáticos citados anteriormente, postula-se que a pronúncia da vogal átona final /o/ apresentava variação durante o século XIX, conforme mostra a Tabela 2 a seguir:

\begin{tabular}{c|c}
$\begin{array}{c}\text { Valor da Vogal Média } \\
\text { Átona Final no PB }\end{array}$ & Século XIX \\
Vogal $/ \mathrm{o} />$ & {$[\mathrm{u}]$} \\
\hline
\end{tabular}

Tabela 2. O valor fonético da vogal /o/ no PB segundo os estudiosos do passado.

Os dados expostos na Tabela 2 demonstram que, no século XIX, a vogal /o/ apresentava uma variante: a vogal alta $[\mathrm{u}]$. Nesse sentido, conjectura-se que a 
elevação da vogal átona final /o/ era o fenômeno que predominava no português brasileiro oitocentista. Além disso, é importante mencionar que nenhum dos autores consultados declara que a vogal átona final /o/ era elidida no português do Brasil ao longo do século XIX.

Diante disso, pode-se dizer que os dados obtidos na presente análise confirmam que a elevação da vogal átona final /o/ é um fenômeno que já atuava no português do Brasil desde o século XIX. Portanto, pode-se afirmar que este processo não é recente na história do português brasileiro.

\subsection{Análise dos Dados da Evidência Indireta}

Tomando-se como base o Princípio do Uniformitarismo 4 (Whitney 1867 / Labov 1994 / Labov 2008 / Joseph / Janda 2003) e os preceitos da Sociolinguística Histórica (Romaine 2009), a presente pesquisa utilizou o passado para explicar o presente com o objetivo de comprovar que certos fenômenos fonológicos existentes na atualidade já ocorreram em tempos mais recuados na história de uma língua. Diante disso, esta pesquisa baseou sua investigação sobre o fenômeno de elevação das vogais médias átonas finais em registros escritos, porque estes são as testemunhas de primeira ordem de um passado linguístico mais distante (Lass 2000).

Além disso, é importante destacar que estudar as vogais médias átonas finais em períodos mais antigos tem demonstrado ser um desafio para os linguistas em decorrência da dificuldade em obter-se evidências sobre sua pronúncia. De acordo com Naro (1973) e Maia (1986), a prática ortográfica é a única fonte existente para obter alguma pista sobre o valor fonético dessas vogais em períodos mais recuados.

A partir destas constatações, o presente exame buscou evidências sobre a elevação das vogais médias átonas finais a partir do levantamento grafemático das letras $<\mathrm{e}>\mathrm{e}<\mathrm{o}>$, em posição de final de palavra, nas correspondências da Coleção Varela.

4 Dentro da Linguística Histórica, o Princípio do Uniformitarismo (Whitney 1867 / Labov 1994 / Joseph / Janda 2003) postula que as forças que operam para produzir a mudança linguística no presente são as mesmas que operaram no passado. O Principio do Uniformitarianismo é uma pré-condição necessária para que o linguista possa proceder à reconstrução histórica da língua que está sendo investigada. Dessa forma, ao utilizar o presente para explicar o passado, o pesquisador poderá inferir, através da observação de processos em curso, como eram os fenômenos que operaram no passado. No entanto, ao propor o uso de métodos de análise variacionista com dados históricos, Romaine (2009) sugere que é possível usar o passado para explicar o presente. 


\subsubsection{Discussão sobre o valor fonético das vogais /e/ e /o/ nos registros escritos}

Para a execução do levantamento grafemático, foram examinadas 1351 correspondências da Coleção Varela. Durante a análise foram coletados poucos registros de palavras grafadas com $<\mathrm{i}>$ ao invés de $<\mathrm{e}>\mathrm{em}$ contexto átono final. Com relação às palavras grafadas $\operatorname{com}<\mathrm{u}>$ no lugar $\mathrm{de}<\mathrm{o}>$ em posição átona final, a análise não constatou nenhuma ocorrência deste tipo de registro. Os dados obtidos a partir do levantamento grafemático da vogal /e/ encontram-se expostos no Quadro 5 a seguir:

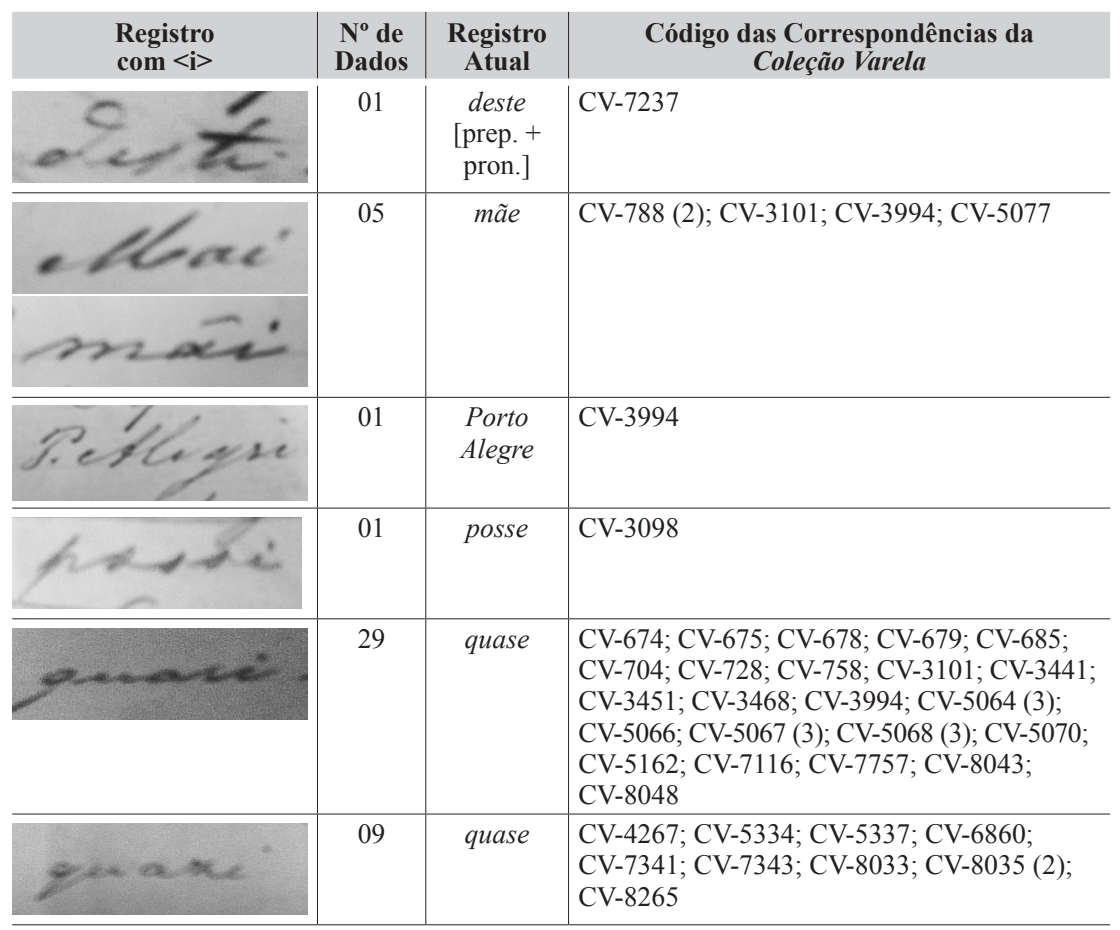

Total de Dados: 46 palavras

Quadro 5. Lista dos dados obtidos com registro de $<\mathrm{i}>$ no lugar de $<\mathrm{e}>$.

A partir desses dados, é possível postular que:

a) a forma desti [de (prep.) + este (pron. demonstr.)] seja um registro com a vogal átona final/e/ sendo realizada como [i]; porque o pronome este é oriundo do latim 
iste (Nascentes 1955: 196 / Pereira 1935: 402), que era grafado com <e $>$ em sua forma primitiva. Com isso, presume-se que o $<\mathrm{i}>$ em desti seja um possível indício da elevação da vogal átona /e/ transferida da fala para a escrita.

b) as formas mãi mai [mãe] sejam registros com a vogal átona final /e/ sendo realizada como vogal alta. Esta hipótese se baseia na seguinte trajetória: a forma mãi vem do latim mater (Torrinha 1939 [1936]: 731) que, posteriormente, no português arcaico, se transformou em madre; esta por sua vez, sofreu novas mudanças, as quais provavelmente por influência da linguagem infantil passou de madre para made dando origem a mãe por assimilação do traço [+nasal] da consoante anterior (Vasconcellos 1911). Segundo Vasconcellos (1911), Torrinha (1939 [1936]) e Nascentes (1955), é possível encontrar em mirandês, no galego e em algumas aldeias de Trás-dos-Montes a forma mai. Diante disso, pode-se inferir que as formas mãi mai sejam possíveis indícios do fenômeno de elevação da vogal /e/ átona final conservados do português trazido pelos colonizadores.

c) o composto P. Alegri [Porto (subst.) + Alegre (adj.)] seja um registro que apresenta a vogal átona final /e/ sendo realizada como [i]; pois o adjetivo alegre é oriundo do latim alacre (Nascentes 1955: 196 / Pereira 1935: 402), que era grafado com $<\mathrm{e}>$ em sua forma primitiva. Desse modo, presume-se que o $<\mathrm{i}>$ em $P$ [orto] Alegri seja um possível indício da elevação da vogal átona /e/.

d) a forma possi [posse] seja um registro que apresenta a vogal átona final /e/ sendo realizada como [i]; porque o substantivo posse é proveniente do latim posse (Nascentes 1955: 411), que era grafado com $<\mathrm{e}>\mathrm{em}$ sua forma primitiva. A partir disso, conjectura-se que o $<\mathrm{i}>$ em possi seja um possível indício da elevação da vogal átona /e/.

e) as formas quasi quazi sejam registros que exibem a vogal átona final /e/ sendo realizada como [i], porque estas formas são oriundas do latim quasi (Nascentes 1955: 425 / Pereira 1935: 186) que era grafado com $\overline{1}$ latino, portanto, trata-se de uma vogal alta conservada do latim. Com o advento da reforma ortográfica no início do século XX, o vocábulo quase passou a ser grafado com $<\mathrm{e}>$ ao invés de $<\mathrm{i}>$. No que diz respeito às grafias quasi com $<\mathrm{s}>$ e quazi $\operatorname{com}<\mathrm{z}>$, isto se trata de variações ortográficas provocadas pela falta de uniformização do sistema ortográfico no português brasileiro do século XIX.

Considerando os resultados da análise dos registros escritos (correspondências), postula-se que, apesar da baixa quantidade de dados obtidos, pode-se inferir que o processo de elevação das vogais médias átonas finais já atuava no português brasileiro oitocentista; pois a grafia "incorreta" da vogal média átona final /e/ permite verificar que o(s) autor(es) do(s) manuscrito(s) provavelmente deixaram transparecer em seus 
textos traços de oralidade. Quanto à análise das obras metalinguísticas e didáticas, apesar de terem sido poucas as obras que serviram aos propósitos do presente estudo, os resultados permitiram constatar que os falantes brasileiros produziam as vogais /e/ e /o/ átonas finais como [i] e [u], respectivamente, durante século XIX.

\section{Conclusão}

Nesta pesquisa, buscou-se investigar e analisar indícios do fenômeno de elevação das vogais médias átonas finais no português brasileiro do século XIX, a partir dos pressupostos teórico-metodológicos da Sociolinguística Histórica (Romaine 2009) e dos preceitos do Princípio do Uniformitarismo (Whitney 1867 / Labov 1994 / Labov 2008 / Joseph / Janda 2003). Para a execução da análise dos dados, utilizaram-se dois tipos de dados empíricos: a evidência direta (obras metalinguísticas e didáticas) e a evidência indireta (correspondências da Coleção Varela).

Tomando como base os resultados da análise, conclui-se que o processo de elevação das vogais médias átonas finais já atuava no português brasileiro durante o século XIX. Portanto, pode-se dizer que a elevação das vogais $\boldsymbol{e}$ e $\boldsymbol{o}$ átonas finais não é um fenômeno linguístico recente na história do português brasileiro.

\section{Referências bibliográficas}

Azevedo, M. M. (2005): Portuguese: a linguistic introduction (Cambridge: Cambridge University Press).

Beal, J. C. (2012): "Evidence from sources after 1500”, em Nevalainen, T. / Traugott, El. (eds.), The oxford handbook of the history of english (New York: Oxford Univserity Press).

Berwanger, A. R. / Leal, J. E. Franklin (2012): Noções de paleografia e de diplomática (Santa Maria: Editora UFSM).

Bisol,L. (2003): Aneutralização das átonas. Revista Letras, n. 61, 273-283. Disponível em: http://ojs.c3sl.ufpr.br/ojs/index.php/letras/article/view/2891 [consult. 20.12.2014].

Cardeira, E. (2009): “A pronúncia do português” em Actas do Simpósio A pronúncia do português europeu cantado (Lisboa: Universidade Nova de Lisboa). Disponível em: http://www.caravelas.com.pt/actas_cardeira.pdf [consult. 23.10.2014].

Carniato, M. C. (2000): A neutralização das vogais postônicas finais na comunidade de Santa Vitória do Palmar. 110 f. Dissertação (Mestrado em Letras) -Universidade Católica de Pelotas, Pelotas. 
Carvalho, M. J. (2005): "On the origin of the final unstressed [i] in Brazilian and other varieties of Portuguese: new evidence in an enduring debate", em Fortescue, Michael D. (org). Historical linguistics 2003 (Amsterdam/Philadelphia: Johns Benjamins Publishing).

Carvalho, J.G. Herculano de (1984): "Nota sobre o vocalismo antigo português: valor dos grafemas e e o em sílaba átona", em Carvalho, J. G. Herculano de, Estudos linguísticos. V. 2 (Coimbra: Coimbra Editora Limitada).

Fitzmaurice, S. / Smith, J. (2012): "Evidence for the history of English: introduction", em Nevalainen, T./ Traugott, E.(eds.). The oxford handbook of the history of english (New York: Oxford Univserity Press).

Fonte, J. Simões (2010). O sistema vocálico do português arcaico visto a partir das Cantigas de Santa Maria. 236 f. Dissertação (Mestrado em Linguística e Língua Portuguesa) - Faculdade de Ciências e Letras, Universidade Estadual Paulista.

Hale, M. (2007): Historical linguistics: theory and method (Malden: Blackwell Publishing).

Hart, T. (1955): Notes on sixteenth-century Portuguese pronunciation. Word, 11, 404-415.

Joseph, B. D. / Janda, R. D. (eds.) (2003): The handbook of historical linguistics (Oxford: Blackwell Publishing).

Joseph, B. D. / Janda, R. D. (eds.) (2011): Historical linguistics and sociolinguistics: strange bedfellows or natural friends? Disponível em: http://www.ling.ohio-state. edu// ddurian/AWAC/Joseph 2011.pdf [consult. 17.06.2014].

Kretzschmar Jr., W.A. / Stenroos, M. (2012): "Evidence from surveys and atlases in the history of English language", em Nevalainen, T. / Traugott, E. (eds.). The oxford handbook of the history of English (New York: Oxford Univserity Press).

Labov, W. (2008) [1972]: Padrões sociolinguísticos (São Paulo: Parábola Editorial).

Labov, W. (1994): Principles of linguistic change: internal factors. V. 1. (Cambridge: Blackwell).

Lass, R. (2000): Historical linguistics and language change (Cambridge: Cambridge University Press).

Maia, C. de Azevedo (1986): História do galego-português: estado linguístico da Galiza e do noroeste de Portugal desde o século XIII ao século XVI (Coimbra: Instituto Nacional de Investigação Científica).

Marquilhas, R., Dúvida sobre o termo vogais "mudas" no século XIX. [mensagem pessoal]. Mensagem recebida por<elianedr19@gmail.com> en 24.01.2015.

Marquilhas, R. (2003): "Mudança analógica e elevação das vogais pretônicas" em Castro, I. / Duarte, I. (orgs.), Razões e emoção. Miscelânea de estudos em homenagem a Maria Helena Mira Mateus (Lisboa: Imprensa Nacional-Casa da Moeda). 
Mcenery, T. / Wilson, A. (2001) [1996]: Corpus linguistics: an introduction (Edinburgh: Edinburgh University Press).

Mendes, U. D. (1953): Noções de paleografia (São Paulo: Arquivo Público do Estado de São Paulo).

Mileski, I. (2013): A elevação das vogais médias átonas finais no português falado por descendentes de imigrantes poloneses em Vista Alegre do Prata-RS. $152 \mathrm{f}$. Dissertação (Mestrado em Letras) - Pontifícia Universidade Católica do Rio Grande do Sul, Porto Alegre.

Milroy, L. / Gordon, M. (2003): Sociolinguistics: method and interpretation (Oxford: Blackwell Publishing).

Monaretto, V. Neto de Oliveira (2013): "Valor fonético das vogais médias postônicas em jornais oitocentistas gaúchos". Diadorim 14, 77-98. Disponível em: http://www. revistadiadorim.letras.ufri.br [consult. 22.06.2014].

Montgomery, M. (1995): "The Linguistic Value of Ulster Emigrant Letters". Ulster Folklife 41, 1-16.

Montgomery, M. (2007): "Variation and historical linguistics" em Bayley, R. / Lucas, C. (eds.), Sociolinguistic variation: theories, methods, and applications (Cambridge: Cambridge University Press).

Naro, A. J. (1973): “A História do e e do o em Português: um estudo de deriva linguística”, em Naro, A. J., Estudos diacrônicos (Petrópolis: Vozes).

Nascentes, A. (1955): Dicionário etimológico da língua portuguêsa. Tomo I (Rio de Janeiro: Oficina Gráfica do Jornal do Commercio).

Nevalainen, T. / Raumolin-Brunberg, H. (2012): "Historical sociolinguistics: origins, motivations, and paradigms", em Hernández, J. M. / Conde-silvestre, J. C., The handbook of historical sociolinguistics (Malden / West Sussex: Wiley-Blackwell).

Penke, M. / Rosenbach, A. (2007): "What counts as evidence in linguistics? Introduction", em Penke, M. / Rosenbach, A. (eds.) What count as evidence in linguistics: the case of innateness (Amsterdam / Philadelphia: John Benjamins Publishing).

Pereira, E. C. (1935) [1915]: Grammatica historica (São Paulo: Companhia Editora Nacional).

Romaine, S. (2009) [1982]: Socio-historical linguistics: its status and methodology (Cambridge: Cambridge University Press).

Rosa, E. da (2015): As vogais médias átonas finais no português brasileiro do século XIX: um estudo baseado em fontes de evidência direta e indireta. $136 \mathrm{f}$. Dissertação (Mestrado em Letras) - Universidade Federal do Rio Grande do Sul. 
Roveda, S. Damiani (1998): Elevação da vogal média átona final em comunidades bilíngues: português e italiano. $87 \mathrm{f}$. Dissertação (Mestrado em Letras) - Pontifícia Universidade Católica do Rio Grande do Sul, Porto Alegre.

Sá, F. Franco de (1915): A lingua portugueza (Maranhão: Imp. Official).

Schalley, A. C. (2002): Practical theories and empirical practice: a linguistic perspective (Amsterdam/Philadelphia: John Benjamins Publishing).

Schendl, H. (2009): Historical linguistics (Oxford: Oxford University Press).

Schmitt, C. J. (1987): Redução vocálica postônica e estrutura prosódica. 139 f. Dissertação (Mestrado em Letras) - Universidade Federal do Rio Grande do Sul, Porto Alegre.

Schneider, E. W. "Investigating variation and change in written documents", em Chambers, J. K. / Trudgill, P. / Schilling-Estes, N. (eds.) (2002), The handbook of language variation and change (Malden: Blackwell Publishing).

Silva, S. Machry da (2009): Elevação das vogais médias átonas finais e não finais no português falado em Rincão Vermelho - RS. 172 f. Dissertação (Mestrado em Letras) - Pontifícia Universidade Católica do Rio Grande do Sul, Porto Alegre.

Stephenson, E. A. (1967): "On the interpretation of occasional spellings", American Dialect Society 48, 33-50.

Torrinha, F. (1939) [1936]: Dicionário português-latino (Porto: Tip. da Editorial Domingos Barreira, $2^{\mathrm{a}}$ edição).

Vasconcellos, J. Leite de (1911): Lições de philologia portuguesa (Lisboa: Livraria Clássica Editora de E. M. A. TEIXEIRA \& C. $\left.{ }^{\text {ta }}\right)$.

Viana, A. dos Reis Gonçalves (1904): Ortografia nacional: simplificação e uniformização sistemática das ortografias portuguesas (Lisboa: Livraria Editora Viuva Tavares Cardoso).

Vieira, M. J. Blaskovski (1994): Neutralização das vogais médias postônicas. $110 \mathrm{f}$. Dissertação (Mestrado em Letras) - Universidade Federal do Rio Grande do Sul, Porto Alegre.

Vieira, M. J. Blaskovski (2002): “As vogais médias postônicas: uma análise variacionista” en Bisol, Leda / Brescancini, Cláudia (eds), Fonologia e Variação: recortes do português brasileiro, 127-160, (Porto Alegre: EDIPUCRS).

Whitney, W. D. (1867): Language and the study of language: twelve lectures on the principles of linguistic science (New York: Charles Scribner \& Company). 


\section{Apêndice A. Lista de obras metalinguísticas e didáticas}

- Methodo Grammatical Resumido da Lingua Portugueza (Casimiro 1803).

- Grammatica Portugueza (Souza 1804).

- Novo Diccionario da Lingua Portugueza ([s.n.] 1806).

- Escola Nova, Christã, e Politica (Sousa e Silva 1813).

- Nôvo Método de Ensinár e Aprendêr a Pronunciação e a Lêitura da Linguágẽe Portuguêza (Couto e Mello 1817).

- Gramática Filosófica da Linguagem Portugueza (Couto e Mello 1818).

- Elementos de Grammatica Portugueza (Ferreira 1819).

- Grammatica Philosophica da Lingua Portugueza (Barbosa 1822).

- Grammatica Portugueza (Moraes Silva 1824).

- Arte da Grammatica Portugueza (Figueiredo 1827).

- Eschola Popular das Primeiras Letras: primeira parte ([s.n.] 1829).

- O Expositor Portuguez (Midosi 1831).

- Grammatica Analytica da Lingua Portugueza (Constancio D.M. 1831).

- Diccionario da Lingua Brasileira (Silva Pinto 1832).

- Grammatica Moderna da Lingua Portugueza ([s.n.] 1840).

- Regras de Grammatica Portugueza (Gibelin / Sicard 1841).

- Reflexões sobre a Lingua Portugueza (Freire 1842).

- Principios de Grammatica Portugueza (Andrade Junior 1844).

- Compendio da Orthografia da Lingua Nacional (Coruja 1848).

- Principios de Grammatica Geral Applicados à Lingua Portugueza (Pestana 1849).

- Grammatica Elementar da Lingua Portugueza (Condurú 1850).

- Metodo Castilho para o Ensino do Ler e Escrever (Castilho 1853).

- Orthographia da Lingoa Portugueza (Portugal 1856).

- Compendio Elementar da Grammatica Portugueza (Veira 1858).

- Genio da Lingua Portugueza: Tomo I (Leoni 1858).

- Genio da Lingua Portugueza: Tomo II (Leoni 1858).

- Grammatica Portugueza (Espada 1861). 
- Nova Grammatica Portugueza (Oliveira 1862).

- Primeiras Linhas de Grammatica Portugueza (Pereira 1863).

- Compendio de Grammatica Nacional (Coruja 1863).

- Grammatica Nacional (Aulete 1864).

- Compendio de Grammatica Portugueza (Macedo 1865).

- A Grammatica Nacional (Sousa 1865).

- A Lingua Portugueza: phonologia, etymologia, morfologia e syntaxe (Coelho 1868).

- Iris Classico (Barreto e Noronha 1868).

- Grammatica da Lingua Portugueza (Mello Morais 1869).

- Advertencias Curiosas sobre a Lingua Portugueza (Barata 1870).

- Compendio da Grammatica Portugueza (Villeroy 1870).

- Grammatica Portugueza (Reis 1871).

- Compendio Orthographico ou Orthographia Resumida ([s.n.] 1871).

- Estudos da Lingua Portugueza (Barata 1872).

- Grammatica Analytica e Explicativa da Lingua Portugueza (Ortiz / Pardal 1873).

- Livro de Leitura para as Escolas Ruraes (Pereira 1875).

- Compendio da Grammatica Philosophica da Lingua Portugueza (Duarte 1877).

- Cartilha Maternal ou Arte de Leitura (Deus 1878).

- Syllabario Portuguez (Galvão 1879).

- Diccionario Contemporaneo da Lingua Portugueza (Aulete 1881).

- Grammatica Portugueza (Ribeiro 1881).

- Novíssima Grammatica Portugueza (Lage 1882).

- Compendio de Grammatica Portugueza da Primeira Idade (Silveira 1884).

- Cartilha da Infância (Pimentel 1886).

- Grammatica Portugueza dos Lyceus (Leite 1887).

- Noções de Grammatica Portugueza (Silva Junior / Andrade 1887).

- Grammatica Analytica da Lingua Portugueza (Massa 1888).

- Grammatica Portugueza Elementar (Nascimento e Silva 1888).

- Grammatica Portugueza (Lapagesse 1889). 
- Grammatica Portugueza (Ribeiro 1889).

- Diccionario Prosodico de Portugal e Brasil (Carvalho / Deus 1890).

- Serões Grammaticais ou Nova Grammatica Portugueza (Ribeiro [1890?]).

- Compendio de Grammatica Portugueza (Almeida 1891).

- Noções de Grammatica Portugueza (Coelho 1891).

- Exposição da Pronuncia Normal Portuguesa para Uso de Nacionais e Estrangeiros (Viana 1892).

- Grammatica Portugueza (Vilhena Alves 1895).

- Noções de Grammatica (Vieira 1897).

- Grammatica Portugueza (Ribeiro 1899).

- Grammatica Nacional ou Methodo Moderno para Aprender a Falar e Escrever sem Erros (Azevedo 1899). 
